\title{
Perceptions of lung cancer screening and smoking behavior change among Chinese immigrants: A systematic review
}

\author{
Fang Lei', Ying Zheng ${ }^{2}$
}

\begin{abstract}
INTRODUCTION Lung cancer is the leading cause of cancer death among Chinese immigrants in the US. Smoking cessation and lung cancer screening are effective ways to decrease lung cancer mortality. This study aims to investigate Chinese immigrants' perceptions of lung cancer screening and to explore the factors/ barriers associated with their smoking behavior/cessation.

METHODS A systematic review design with narrative methods was used. Electronic literature databases, including PubMed, CINAHL and Google Scholar were searched.

RESULTS A total of 11 articles met the search criteria. Methodological rigor of the studies was evaluated by Bowling's checklist and Critical Appraisal Skills Program checklist. Data search revealed that a limited amount of research has been done on Chinese immigrants' perceptions of lung cancer screening. Factors influencing their smoking behavior included personal characteristics, psychological status, acculturation, and cues from external environment. Barriers to their smoking cessation behavior included language barriers, individual's unwillingness to use smoking cessation assistance methods, healthcare environment's insufficiency to counter pro-smoking norms, lack of social support, and wrong personal beliefs. concLusions Findings from this study could help healthcare providers to design culturally tailored lung cancer screening programs and smoking cessation projects to decrease morbidity and mortality rates of lung cancer among Chinese immigrants.
\end{abstract}

\begin{tabular}{l} 
AFFILIATION \\
1 University of California Los \\
Angeles, Los Angeles, United \\
States \\
2 Shenzhen Nanshan \\
Medical Group Headquarter, \\
Shenzhen, China \\
CORRESPONDENCE T0 \\
Ying Zheng. Department \\
of Health Care Quality \\
Improvement, Shenzhen \\
Nanshan Medical Group \\
Headquarter, 11 Changxing \\
Rd, Nanshan District, \\
Shenzhen, China. E-mail: \\
9984277@ @q.com \\
ORCID ID: https://orcid. \\
org/0000-0002-8508-4885 \\
KEYwORDS \\
lung cancer screening, \\
smoking, Chinese immigrants, \\
smokers, systematic review \\
\hline Received: 1 October 2020 \\
Revised: 27 January 2021 \\
Accepted: 22 February 2021
\end{tabular}

\section{INTRODUCTION}

Chinese Americans are the largest Asian group in the US. It is one of the most rapidly growing ethnic groups in the US ${ }^{1}$. Accounting for $23 \%$ of the Asian American subpopulation, Chinese Americans numbered approximately 4 million in $2010^{1}$. Most of the Chinese Americans reside in the state of California, with nearly 1.5 million in 2010 , which is a $30 \%$ increase in population from 2000 to $2010^{1}$.

Chinese immigrants are the largest group among Chinese Americans ${ }^{2}$. Of those who identify themselves as being Chinese American, the majority (69\%) are immigrants, and the rest (31\%) are American-born ${ }^{3}$. In 2013, Chinese immigrants accounted for $5 \%$ of all new immigrants to the US ${ }^{4}$. Since 1980, the population of Chinese immigrants in the US has grown nearly sevenfold, reaching almost 2.5 million in 2018 , or $5.5 \%$ of the overall foreign-born population ${ }^{5}$. Although some cancer research involving Chinese immigrants has been done, most aggregated Chinese Americans, other Asian Americans and Pacific Islanders into one single group (AANPI), or integrated Chinese immigrants and native-born Chinese Americans into one group, potentially masking important subgroup and regional differences among specific Asian subgroups ${ }^{1,6}$.

In the US, lung cancer is the leading cause of cancer death ${ }^{7}$. It is also the most common cause of cancer death among Chinese Americans and is the 
second and fourth most common cancer among US Chinese men and women, respectively ${ }^{8}$. Lung cancer accounted for approximately $30 \%$ of all cancer-related deaths in Chinese Americans ${ }^{9}$.

Smoking cessation and lung cancer screening with low-dose computed tomography are two efficient methods to decrease the mortality rate of lung cancer. Compared to chest $\mathrm{X}$-rays, lung cancer screening with low-dose computed tomography can significantly reduce the mortality rate of lung cancer by $20 \%^{10,11}$ and increase patients' five-year survival rates from $15 \%$ to $52 \%^{12}$. Since 2013 , the US Preventive Service Task Force has recommended certain high risk populations to receive low-dose computed tomography to screen for lung cancer ${ }^{13}$. From 2015, both private and public health insurances began to cover lung cancer screening with low-dose computed tomography for eligible populations, with physicians' order and shared decision-making documents ${ }^{14,15}$. However, given the changed landscape of insurance coverage, the use rate of lung cancer screening remains low among the US eligible population. The percentage of eligible population who received lung cancer screening with low-dose computed tomography only increased from $3.3 \%$ in 2010 to $3.9 \%$ in $2015^{16}$. Although no study has reported the rate of lung cancer screening among Chinese Americans or Chinese immigrants, it appears that the rate of lung cancer screening is low among these populations.

Cigarette smoking is a major cause of lung cancer ${ }^{17}$, which contributes to $87 \%$ of all lung cancer related deaths among the US population, with a mortality rate of up to $90 \%$ in males and $65 \%$ in females ${ }^{18}$. Since 1995, smoking has been banned in all enclosed workplaces in California; in 2012, restriction of smoking in residential dwelling units was passed and written into California law ${ }^{19}$. In the US, since 2009, a total of 30 states have enacted laws that require $100 \%$ smoke-free workplaces and/or restaurants and/or bars ${ }^{20}$. Chinese immigrants, who immigrated from a country with a socioculture context accepting tobacco use, to the US, a country with a socioculture context not accepting tobacco use, may change their smoking behavior after immigration, with their social environment after immigration playing a key role ${ }^{21}$.

As the primary and secondary prevention methods of lung cancer, smoking cessation and lung cancer screening with computed tomography, respectively, are important components for lung cancer intervention programs. Investigating Chinese immigrants' smoking behavior change and exploring their perceptions of lung cancer screening could potentially help healthcare providers to design culturally tailored lung cancer screening and smoking cessation programs to decrease the mortality rate of lung cancer among this population.

To date, studies about Chinese immigrants' perceptions of lung cancer screening and smoking behavior change are limited. Since the evidencebased effective lung cancer screening and smoking cessation are widely recommended, an understanding of Chinese immigrants' perceptions of lung cancer screening and smoking behavior change is essential. The purpose of this systematic review was to investigate Chinese immigrants' perceptions of lung cancer screening as well as to explore the factors/ barriers associated with their smoking behavior/ cessation. This study will provide insights into evidence related to Chinese immigrants' lung cancer screening and smoking behavior change. It will help to decrease the morbidity and mortality of lung cancer among this population.

\section{METHODS}

A systematic review design with narrative method was used. Electronic literature databases, including PubMed, CINAHL and Google Scholar were searched. Studies were selected if they met the following inclusion criteria: 1) peer-reviewed; 2 ) focused on perceptions of lung cancer screening or smoking behavior change among Chinese immigrants in the US; and 3) published in English. Studies were excluded if they were: 1) not targeted at Chinese immigrants in the US; and 2) informal articles (e.g. letter to editors, commentaries, etc.) without data support. The following keywords were used to identify potentially eligible studies: lung cancer screening, low dose computed tomography, low dose CT, LDCT, Chinese immigrants, smokers, perception, knowledge, attitude, belief, perspective, smoking, smoking behavior, barriers, factor, and smoking behavior change. Equivalent index terms and freetext words were also used. The titles of the studies were filtered first, then the inclusion and exclusion criteria were applied for further selection and finally the abstracts and texts were inspected. Features, 
including purpose, design, sample, setting, methods, results, discussion, and limitations were extracted from each study. Procedural rigor and methodology were considered for each study design.

\section{RESULTS}

\section{Studies selection}

Initially, 382 references were retrieved from the databases, after adjustment of repeated articles and inspection of abstract and text, a total of 11 articles were selected to be included in the study (Figure 1 ). Results in the study were reported following the PRISMA approach (Supplementary file) ${ }^{22}$. Given the heterogeneity of the descriptive characteristics, purpose and outcome measures in the studies, the included studies were synthesized using a narrative approach.

\section{Data evaluation}

The methodological rigor of the included articles was evaluated using Bowling's checklist ${ }^{23}$ for quantitative studies and the Critical Appraisal Skills Program (CASP) checklist $^{24}$ for qualitative studies. Bowling's checklist is a systematic appraisal tool to evaluate a study's clarity of aims, objectives, methods and appropriateness of data analysis. It provides a comprehensive checklist of 20 evaluation criteria rather than a scoring system to assess the quality of quantitative studies. The Critical Appraisal Skills

\section{Figure 1. Flow chart of the study selection process}

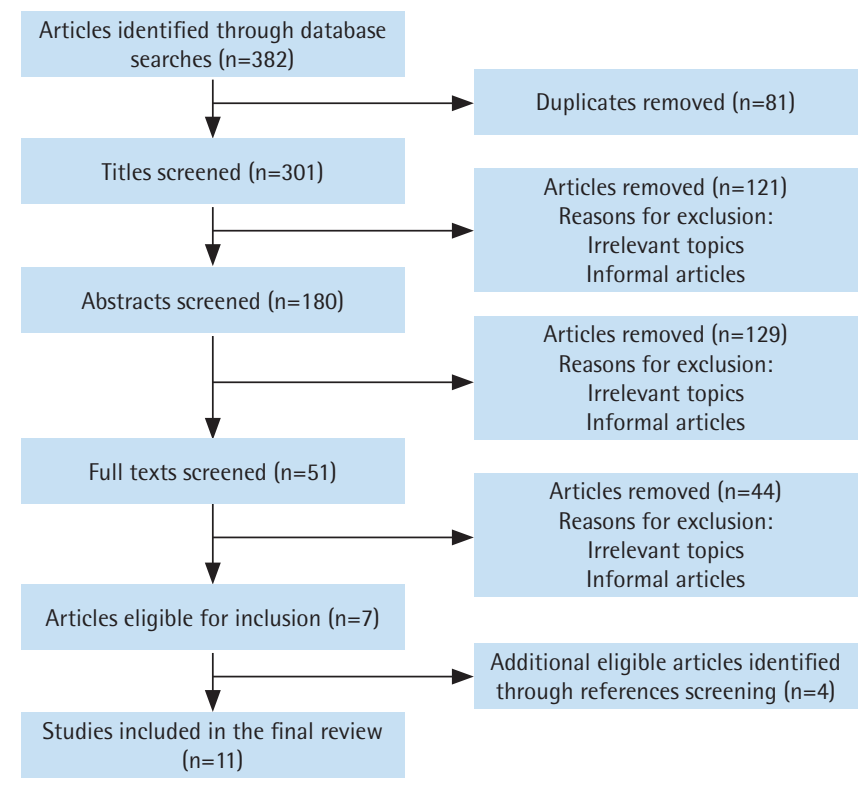

Program (CASP) checklist was used to assess the quality of all the included qualitative studies. All 11 studies had limitations, e.g. none of the articles discussed generalizability of findings to other populations. The methodological critique appraisal process was reviewed by the authors independently. Disagreements were reconciled by mutual agreement.

Study characteristics

For the 11 studies included in this review (Table 1 ), five were cross-sectional survey studies ${ }^{25-29}$, two were qualitative studies ${ }^{30,31}$, one was a secondary data analysis study ${ }^{32}$, one was a mix-method study $^{33}$, one was a longitudinal observational study ${ }^{34}$ and one was a randomized control study ${ }^{35}$. The publication year of the studies were from $2002^{25}$ to $2017^{31}$. The sample size ranged from 2630 to $3249^{32}$.

\section{Perceptions of lung cancer screening}

To date, there is a limited number of studies on the topic of Chinese immigrants' perceptions of lung cancer screening. However, among the US population, previous research has explored US general smokers' perceptions of lung cancer screening and identified several factors that may influence high-risk US population's behaviors related to lung cancer screening, including perceived low value of lung cancer screening with low-dose computed tomography, lack of knowledge about lung cancer screening, wrong beliefs (e.g. fatalistic beliefs), distrust of medical system, stigma (e.g. perceived blame and stigma associated with lung cancer and smoking), negative expectations of lung cancer screening (e.g. radiation exposure, falsepositive results, over-diagnosis, procedure and diagnose-related anxiety or distress), inconvenience (e.g. lack of transportation, time constraints, and appointment conflicts), economic barriers (e.g. insurance coverage), demographic barriers (e.g. age, gender, smoking history), instrumental barriers (e.g. concerns about accuracy of low-dose computed tomography, uncertainty regarding the benefit of lung cancer screening, acceptance level of trial evidence and guidelines, and concerns about the procedure), infrastructural barriers (e.g. insufficient identified screening centers and personnel, lack of an active lowdose computed tomography screening program and equipment), and lack of information from healthcare providers $^{36-44}$. 
Table 1. Study characteristics for the included studies

\begin{tabular}{|c|c|c|c|c|}
\hline $\begin{array}{l}\text { First } \\
\text { author }\end{array}$ & Year & Design & Sample & $\begin{array}{l}\text { Identified factors/barriers related to smoking } \\
\text { behavior/cessation }\end{array}$ \\
\hline Yu et al. ${ }^{25}$ & 2002 & $\begin{array}{l}\text { Cross-sectional } \\
\text { survey study }\end{array}$ & 644 Chinese Americans & $\begin{array}{l}\text { Age } \\
\text { Education level } \\
\text { Knowledge level about early cancer warning symptoms } \\
\text { and signs } \\
\text { Social environment } \\
\text { Whether to use a non-Western clinic or physician for } \\
\text { health care }\end{array}$ \\
\hline
\end{tabular}

Fu et al. ${ }^{26} \quad 2003$ Cross-sectional survey study

\begin{tabular}{|c|c|c|}
\hline $\begin{array}{l}\text { Ma et } \\
\text { al. }{ }^{27}\end{array}$ & 2004 & $\begin{array}{l}\text { Cross-sectional } \\
\text { survey study }\end{array}$ \\
\hline $\begin{array}{l}\text { Shelley et } \\
\text { al. }{ }^{28}\end{array}$ & 2004 & $\begin{array}{l}\text { Cross-sectional } \\
\text { survey study } \\
\text { using in-person, } \\
\text { household-based } \\
\text { interviews }\end{array}$ \\
\hline $\begin{array}{l}\text { Sussman } \\
\text { and } \\
\text { Truong } \\
\text { Tra }\end{array}$ & 2011 & $\begin{array}{l}\text { Cross-sectional } \\
\text { survey study }\end{array}$ \\
\hline $\begin{array}{l}\text { Petersen } \\
\text { et al. }{ }^{30}\end{array}$ & 2016 & $\begin{array}{l}\text { Qualitative study } \\
\text { using in-depth } \\
\text { dyadic and } \\
\text { individual interviews }\end{array}$ \\
\hline $\begin{array}{l}\text { Saw et } \\
\text { al. }{ }^{31}\end{array}$ & 2017 & $\begin{array}{l}\text { Qualitative study } \\
\text { using focus group } \\
\text { interviews }\end{array}$ \\
\hline
\end{tabular}

Gorman 2014 Secondary data

et al. ${ }^{32} \quad$ analysis study

FitzGerald 2015 Mix-method study et al. ${ }^{33}$

\footnotetext{
Tsoh et 2003 Longitudinal

al. $^{34}$ observational study
}

541 Chinese American adults (aged $\geq 18$ years) attending four pediatric, medical, or dental practices located in Philadelphia's Chinatown

1374 Chinese Americans

\section{Chinese Americans}

364 first-generation immigrants living in New York City

13 immigrant smoker-family member pairs of Vietnamese ( $n=9$ dyads, 18 individuals) and Chinese ( $\mathrm{n}=4$ dyads, 8 individuals) descent, including seven current and six former smokers and 13 family members

Seven focus-group interviews with 63 Smoking cessation suggestions from healthcare Chinese immigrants

3249 Latino and Asian American immigrants

199 Chinese smokers who resided in northern California

\section{Acculturation}

English language proficiency level

Gender

\section{Acculturation}

Gender

Tobacco-related knowledge level

Age

Acculturation

\section{Acculturation}

Gender

Duration of residence

English language proficiency level

Lack of social support (e.g. self-isolation, the limited support systems in their community or work/school environments, the scarce or non-existent information about how to stop smoking)

Commonality of smoking in their community

Smoking
providers

Realized changes in environmental regulation Social acceptability of smoking after immigration Perceived benefits to improve children's health and achieve family harmony

Irritating odor

Negative nonverbal reactions (e.g. people covering their noses and mouths)

Environments with pro-smoking norms

Duration of US residence

Connections with others (e.g. English language proficiency and citizenship acquisition)

Psychological status (e.g. stress)

Gender

Qualitative: 16 Chinese smokers Education level participated in focus groups interview Knowledge level of smoking consequences Quantitative: 167 current Chinese immigrant smokers (137 males and 30 females)

\section{Age}

Language and literacy issue

Wrong personal beliefs (e.g. they can quit on their own whenever they decide to; perceived minimal health risk of smoking; smoking relaxed them and helped them feel less stress)

Psychological status (e.g. depressive disorders, dysthymia) 
Table 1. Continued

\begin{tabular}{|c|c|c|c|c|}
\hline $\begin{array}{l}\text { First } \\
\text { author }\end{array}$ & Year & Design & Sample & $\begin{array}{l}\text { Identified factors/barriers related to smoking } \\
\text { behavior/cessation }\end{array}$ \\
\hline $\begin{array}{l}\text { Wu et } \\
\text { al. }{ }^{35}\end{array}$ & 2009 & $\begin{array}{l}\text { A two-group } \\
\text { experimental } \\
\text { random design with } \\
\text { baseline assessment } \\
\text { and follow-up } \\
\text { measures }\end{array}$ & 122 Chinese smokers & $\begin{array}{l}\text { Limited resources for pleasure } \\
\text { Lack of alternatives to smoking }\end{array}$ \\
\hline
\end{tabular}

Although reports about Chinese immigrants' perceptions of lung cancer screening are lacking, previous studies conducted among Chinese immigrants showed multiple perceptual barriers existed toward cancer screening ${ }^{45}$, which may present in their perceptions of lung cancer screening as well. Some Chinese community residents were not familiar with the preventive measure of cancer screening and had not received common cancer screening before ${ }^{45}$. In addition, language barriers and cultural influence (e.g. 'yin and yang', 'qi') had a negative impact on Chinese immigrants' perceptions toward cancer screening behaviors ${ }^{46}$. Misconceptions about cancer screening were also widespread among Chinese immigrants (e.g. screening for cancers can lead to cancers $)^{45}$.

\section{Smoking behavior change among Chinese immigrants}

China has the largest number of smokers in the world ${ }^{47}$. It has more than $50 \%$ of adult male smokers ${ }^{47}$. In contrast to smokers in China, the rate of smoking prevalence among Chinese immigrants is much lower. There is evidence that immigration may lead to a reduction in smoking ${ }^{48-50}$. In some studies, Chinese men outside their original country have been labeled 'model' immigrants in smoking reduction or cessation after migrating to a region or country with low smoking rates ${ }^{51}$. A study with Chinese immigrants in California identified that $52.5 \%$ of Chinese smokers had quit smoking and remained abstinent for one year ${ }^{51}$. Although this quit level was comparable to the quit rate for California smokers in general $(53.3 \%)$, the quit rate among Chinese immigrants was about seven times the quit rate among smokers in China ${ }^{51}$. Similar findings were also reported in other studies. Results showed Chinese immigrant smokers tend to reduce their smoking more than other subpopulations in the $\mathrm{US}^{48,52}$.
Interestingly, as the duration of US residence became longer, smoking among Asian immigrants (including Chinese immigrants) increased in both prevalence and frequency, despite the context of a smoke-free policy in the US ${ }^{32}$, which was notable among female immigrants ${ }^{53}$. Previous research has found that immigrants with longer US residence or greater acculturation to US society have worse health and risk factors (e.g. smoking prevalence) than those with shorter residence or less acculturation ${ }^{53,54}$.

\section{Factors influencing Chinese immigrants' smoking behaviors}

Previous studies have identified various sociocultural factors, including cultural beliefs, lack of cancer awareness and education, which may lead to higher rates of smoking among immigrant populations ${ }^{55}$. Among Chinese immigrants, results showed factors related to personal characteristics, psychological status, acculturation, and cues from external environment that may influence their smoking behaviors.

\section{Personal characteristics}

Personal characteristics, including age, level of education, gender, knowledge level about early cancer warning symptoms and signs, English language proficiency level, whether to use a non-Western clinic or physician for healthcare, and duration of residence, were significantly associated with Chinese immigrants' smoking attitude and smoking behavior ${ }^{25,26,29}$. According to Shelley et al..$^{28}$, possessing a high level of tobacco-related knowledge and being aged $\geq 35$ years predicted smoking cessation behavior among Chinese Americans. Both were positively associated with the smoking cessation behavior ${ }^{28}$. These results may potentially be also generalized to Chinese immigrants. Also, current smokers relative 
to former smokers were more likely to be recent immigrants and to be from mainland China ${ }^{28}$. A study also showed that higher education and better knowledge of smoking consequences contributed to having a greater intent to quit smoking among Chinese immigrants ${ }^{25}$. In addition, fatherhood may be positively associated with smoking cessation among Chinese immigrants ${ }^{31}$. Due to concern about the impact of smoking on the health of young children, being a father or prospective father prompted the Chinese smoker to quit or reduce smoking ${ }^{31}$. Furthermore, researchers found that, regardless of the amount of time spent in the US, immigrants who form strong local connections, evidenced by English language proficiency and citizenship acquisition, have increased rates of smoking cessation ${ }^{32}$.

\section{Psychological status}

Psychological status may impact Chinese immigrant smokers' smoking behavior. Previous studies showed that Chinese American smokers, including Chinese immigrant smokers, reported higher depressive symptoms than Chinese Americans ${ }^{34}$. A higher rate of major depressive disorders (30.3\%) and dysthymia (11.6\%) during Chinese immigrants' lifetime ${ }^{34}$ may influence their smoking behavior. Results showed that more stressed immigrants were more likely to smoke ${ }^{32}$. However, Asian women who immigrated to the US, including Chinese female immigrant smokers, tended to experience a higher increase in smoking after immigration compared with their male counterparts, given the decreased distress from smoking stigma in the changed culture context ${ }^{32}$.

\section{Acculturation}

Acculturation has a significant impact on Chinese immigrants' smoking behaviors ${ }^{27}$. While more acculturated male adults were less likely to smoke than the less acculturated male adults, less acculturated adult females and youth were less likely to smoke than the more acculturated females and youth ${ }^{27}$. Overall, Chinese immigrant males were more likely to smoke than Chinese immigrant females regardless of acculturation status ${ }^{27}$. Furthermore, acculturation was positively associated with never smoking among men but not associated with smoking cessation ${ }^{28}$. While male Chinese American including Chinese immigrant ever smokers were less acculturated relative to never smokers, acculturation was not related to current versus former smoking status ${ }^{28}$.

\section{Cues from external environment}

Cues from external environment, including social and cultural acceptability of smoking, may influence Chinese immigrant smokers' smoking behavior. A qualitative study conducted by Saw et al. ${ }^{31}$ among Chinese-speaking smokers and non-smokers in California showed that factors influencing their intention of smoking cessation included smoking cessation suggestions from healthcare providers, realized changes in environmental regulation, social acceptability of smoking after immigration, perceived benefits to improve children's health and achieve family harmony, and irritating odor. According to Saw et al. ${ }^{31}$, both smokers and non-smokers in the US were aware that smoking in public was not viewed favorably. Several smokers reported that their smoking behaviors sometimes met with negative nonverbal reactions (e.g. people covering their noses and mouths $)^{31}$. Due to such external nonverbal reactions, one smoker reported quitting smoking, and others reported decreased cigarette consumption ${ }^{31}$. Furthermore, nonsmokers noted that their smoking household members reduced or quit smoking after immigrating to the US, and several stated that visiting China had resulted in relapsing or increasing the smoking intensity ${ }^{31}$.

\section{Barriers to smoking cessation among Chinese immigrant smokers}

\section{Language barrier}

A previous study showed that language and literacy issues were a barrier for Chinese immigrant smokers to access smoking cessation information and to obtain useful information from social media ${ }^{33}$. Older Chinese immigrant smokers (aged $\geq 35$ years) mentioned that they had limited exposure to public sources of information on cessation services in their native language ${ }^{33}$. Younger Chinese immigrant smokers (aged $<35$ years) mentioned lacking disseminated messages in their native language related to smoking cessation and quitting services through social media (e.g. text messaging) ${ }^{33}$.

Unwillingness to use smoking cessation assistance methods

A study showed Chinese immigrant smokers rarely 
used smoking cessation aids or services after immigrating to the new country, despite both exsmokers and current smokers had reported making more than one quit attempt ${ }^{30}$. Few Chinese immigrant smokers reported taking or being advised to take medications (e.g. patches or nicotine gum) to aid in smoking cessation ${ }^{31}$. Barriers to seeking smoking cessation assistance services among Chinese immigrant smokers may derive from two aspects, firstly practical barriers, which include lack of available information on smoking cessation assistance and difficulty in accessing smoking cessation assistance, and secondly cultural barriers, which include denial of physiological addiction to nicotine, mistrust in the effectiveness of smoking cessation assistance, tendency of self-reliance in solving problems, and concern of privacy revelations related to utilization of smoking cessation assistance ${ }^{30}$.

\section{Healthcare environment's insufficiency to counter pro- smoking norms}

Most of the Chinese-speaking smokers and nonsmokers in California, including Chinese immigrant smokers, reported being unable to sustain smoking cessation $^{32}$. Although they had tried to quit smoking when they were acutely ill and were advised to quit smoking by medical providers, once they were no longer sick, especially if they continued to socialize in environments with pro-smoking norms, they returned to smoking and rationalized their behaviors ${ }^{32}$.

\section{Lack of social support}

Chinese immigrant smokers reported lack of social support to quit smoking, including self-isolation and the limited support systems in their community or work/school environments, as well as scarce or nonexistent information about how to stop smoking ${ }^{30,35}$. They reported the commonality of smoking in their community and limited resources for pleasure, as well as lack of alternatives to smoking, urged them to smoke and be linked to their peers ${ }^{30,35}$.

\section{Wrong personal beliefs}

Wrong personal beliefs, such as 'they can quit on their own whenever they decide to' and perceived minimal health risk of smoking hindered Chinese immigrant smokers' smoking cessation behaviors ${ }^{33}$. In the study conducted among 167 current Chinese immigrant (137 males and 30 females) smokers, the main reasons of $62 \%$ of the participants to smoke regularly were the beliefs that smoking 'relaxed them' and 'helped them feel less stress'33.

\section{DISCUSSION}

This systematic review explored Chinese immigrants' perceptions of lung cancer screening and identified the factors/barriers related to their smoking behaviors/ cessation. It provides evidence for the development of lung cancer screening programs for Chinese immigrants ${ }^{30}$. The identified factors influencing Chinese immigrants' smoking behaviors as well as barriers towards their smoking cessation behavior could potentially help to design culturally adapted smoking cessation intervention programs for Chinese immigrant smokers and facilitate the implementation of tobacco control policy both in the US and China.

Chinese immigrants' smoking behaviors were influenced by multiple factors, including personal characteristics, psychological factors, and cultural factors (acculturation, external environment). Upon immigration, the smoking rate among Chinese immigrants became much lower than their counterparts in China, which is potentially due to the self-selection bias related to the Health Migration Effect $^{56}$, or some combination of underdiagnoses of health conditions subsequent to immigration, lower susceptibility, healthier ingrained behaviors, or a likelihood of returning to their host country upon becoming sick ${ }^{57}$. However, with the duration of US residence becoming longer, smoking among Chinese immigrants increased in both prevalence and frequency ${ }^{32}$. Exceptionally, in the same study ${ }^{32}$, researchers also found that, immigrants who form strong local connections, such as English language proficiency and citizenship acquisition, benefit from reduced smoking regardless of the amount of time spent in the US. One possible reason for this is that the immigrants with higher English language proficiency and citizenship acquisition are less stressed and have higher socioeconomic standing ${ }^{32}$. Also, smoking behavior change among Chinese immigrants may be influenced by psychological factors and cultural factors. A stressful external environment related to the sociocultural change as well as smoking control policy restriction may influence Chinese immigrant smokers' smoking behavior, e.g. Chinese female immigrant smokers usually experienced an increase 
in smoking after immigration. It may be possibly due to the psychological changes in culture context related to the decreased distress from smoking stigma among women ${ }^{32}$ and/or the sociocultural change that acculturated their smoking behaviors ${ }^{27}$.

Multiple barriers for smoking cessation exist among Chinese immigrant smokers. As a population who use Chinese as the first language, most of Chinese immigrants had low English language proficiency and low heath literacy ${ }^{58,59}$, which may impact their ability to get access to smoking cessation services, obtain information or resources about smoking cessation, receive support from social services or healthcare providers, etc. This may particularly be reflected by the low utilization rate of smoking cessation assistance methods among this population. Their ability to get access to the smoking cessation assistance services may be restricted by the language barrier. In addition, connections with the pro-smoking peers may hinder their smoking cessation progress and trigger smoking relapse thoughts. Lack of social support and wrong personal beliefs may also leave them battling smoking cessation unaided. To increase smoking cessation rates among this population, culturally tailored smoking cessation programs should be developed in the Chinese language with appropriate health literacy levels. Smoking cessation assistance services and social support should also be offered at the community level to help Chinese immigrant smokers to connect with necessary resources.

\section{Limitations}

There are some limitations in this review. First, data in this study were synthesized using a narrative method rather than a meta-analysis method. As such, our findings cannot be used to identify the specific relationships between smoking behavior change and various related factors. Second, we included studies only from peer-reviewed English-language journals, which may have restricted our findings and biased the data. Third, due to the scarcity of studies conducted on Chinese immigrants' perceptions of lung cancer screening, information provided in this study on this topic is limited as well.

\section{Future research}

To date, a limited number of studies have been conducted on Chinese immigrants' perceptions of lung cancer screening. Although we generally synthesized relevant findings about US population's perceptions of lung cancer screening in this study, due to the cultural differences, future studies exploring Chinese immigrants' perspectives of lung cancer screening are needed. No evidence was found about the relationship between comparative purchase cost of cigarettes in the US and Chinese immigrants' smoking cessation. Although the economical/financial factor was always deemed as an important element influencing smokers' smoking behavior, no study has been conducted on this topic among Chinese immigrants in the US. Future research is needed to explore Chinese immigrants' smoking behavior change and the comparative purchase cost of cigarettes. Future research focusing on lung cancer screening and smoking behavior change among Chinese immigrants should address the changes in sociocultural context and language barriers for them accessing smoking cessation information. The tobacco culture which was cultivated in the long history of Chinese culture and the English language barriers may also hinder their use of lung cancer screening. Further exploration of Chinese immigrants' perceptions of lung cancer screening and smoking behavior change is necessary and essential for facilitating the use of lung cancer screening and smoking cessation among this population.

\section{CONCLUSIONS}

This systematic review summarized Chinese immigrants' perceptions of lung cancer screening, factors influencing their smoking behavior change and barriers to their smoking cessation. It provided evidence and suggestions for facilitating lung cancer screening and smoking cessation programs among Chinese immigrants. Future research aiming to explore Chinese immigrants' perspectives toward lung cancer screening are needed. Factors including individual's personal characteristics, psychological status, acculturation and cues from external environment should be considered when smoking cessation programs are implemented. Language barriers, individual's unwillingness to use smoking cessation assistance methods, healthcare environment's insufficiency to counter pro-smoking norms, lack of social support, and wrong personal beliefs should be considered when smoking cessation consultations are given. 


\section{REFERENCES}

1. Torre LA, Sauer AMG, Chen MS, Jr, Kagawa-Singer M, Jemal A, et al. Cancer Statistics for Asian Americans, Native Hawaiians, and Pacific Islanders, 2015: Convergence of incidence between males and females.CA Cancer J Clin. 2016;66(3):182-202. doi:10.3322/caac.21335

2. Hoeffel E, Rastogi S, Kim M, Shahid H. The Asian Population: 2010. Washington, DC: U.S. Department of Commerce Sensus Bureau; 2012. https://www.census. gov/prod/cen2010/briefs/c2010br-11.pdf. Accessed October 1, 2020.

3. United States Census Bureau. 2011-2013 ACS 3-year Estimates. https://www.census.gov/programs-surveys/ acs/technical-documentation/table-and-geographychanges/2013/3-year.htmlUpdated June 7, 2019. Accessed September 25, 2020.

4. Hooper K, Batalova J. Chinese Immigrants in the United States in 2013. Migration Policy Institute. https://www. migrationpolicy.org/article/chinese-immigrants-unitedstates--2013. Published January 28, 2015. Accessed October 1, 2020.

5. Echeverria-Estrada C, Batalova J. Chinese Immigrants in the United States. https://www.migrationpolicy.org/ article/chinese-immigrants-united-states-2018. Published January 15, 2020. Accessed October 1, 2020.

6. Jin H, Pinheiro PS, Xu J, Amei A. Cancer incidence among Asian American populations in the United States, 2009-2011. Int J Cancer. 2016;138(9):2136-2145. doi:10.1002/ijc.29958

7. American Cancer Society. Cancer Facts \& Figures 2018. https://www.cancer.org/research/cancer-facts-statistics/ all-cancer-facts-figures/cancer-facts-figures-2018. html\#: :text=Estimated\%20numbers $\% 20$ of $\% 20$ new $\% 20$ cancer,deaths $\% 20 \mathrm{in} \% 20$ the $\% 20$ United $\% 20$ States.). Accessed October 1, 2020.

8. Gomez SL, Yang J, Lin S-W, McCusker M, Sandler A, Patel M, et al. Lung Cancer Survival Among Chinese Americans, 2000 to 2010. J Glob Oncol. 2016;2(1):3038. doi:10.1200/JGO.2015.000539

9. Thompson CA, Gomez SL, Hastings KG, Kapphahn K, Yu P, Shariff-Marco S, et al. The Burden of Cancer in Asian Americans: A Report of National Mortality Trends by Asian Ethnicity. Cancer Epidemiol Biomarkers Prev. 2016;25(10):1371-1382. doi:10.1158/1055-9965.EPI-16-0167

10. Tota J, Ramanakumar A, Franco E. Lung cancer screening: review and performance comparison under different risk scenarios Lung. 2014;192(1):55-63. doi:10.1007/s00408-013-9517-x

11. Wender R, Fontham ETH, Barrera E, Colditz GA, Church TR, Ettinger DS, et al. American Cancer Society lung cancer screening guidelines. CA Cancer J Clin. 2013;63(2):107-117. doi:10.3322/caac.21172

12. McCarthy M. Task force recommends CT lung cancer screening for high risk smokers and ex-smokers. BMJ. 2014;348(23):g56. doi:10.1136/bmj.g56
13. U.S. Preventive Services Task Force. Lung Cancer: Screening. https://www.uspreventiveservicestaskforce. org/uspstf/document/RecommendationStatementFinal/ lung-cancer-screening. Published December 31, 2013. Accessed October 1, 2020.

14. Bindman AB. Lung Cancer Screening and Evidence-Based Policy. JAMA Health Forum. https://jamanetwork.com/ channels/health-forum/fullarticle/2760609. Accessed September 25, 2020.

15. Volk RJ, Hawk E, Bevers TB. Should CMS Cover Lung Cancer Screening for the Fully Informed Patient?. JAMA. 2014;312(12):1193. doi:10.1001/jama.2014.12709

16. Jemal A, Fedewa SA. Lung Cancer Screening with Low-Dose Computed Tomography in the United States-2010 to 2015. JAMA Oncol. 2017;3(9):1278. doi:10.1001/jamaoncol.2016.6416

17. Xie A, Croce B, Tian DH. Smoking and lung cancer. Ann Cardiothorac Surg. 2014;3(2):221. doi:10.3978/j.issn.2225-319X.2014.03.09

18. Li CC, Matthews AK, Dong X. Examination of Chronic Smoking Behavior and Eligibility for Low-Dose Computed Tomography for Lung Cancer Screening Among Older Chinese Male Smokers. J Gerontol A Biol Sci Med Sci. 2017;72(Suppl 1):S22-S25. doi:10.1093/gerona/glw202

19. California State Legislature. CIVIL CODE - CIV: CHAPTER 2. Hiring of Real Property [1940 - 1954.06]. https://leginfo.legislature.ca.gov/faces/codes_ displaySection. $x$ html?lawCode $=$ CIV $̧$ ionNum $=1947.5$. Accessed September 25, 2020.

20. Institute of Medicine (US) Committee on Secondhand Smoke Exposure and Acute Coronary Events. Secondhand Smoke Exposure and Cardiovascular Effects: Making Sense of the Evidence. Washington, DC: National Academies Press (US); 2010. doi:10.17226/12649

21. Yu L. "It's not a life or death thing": A grounded theory study of smoking decisions among Chinese Americans. Qualitative Report. 2017;22(3):797-817. https://nsuworks. nova.edu/cgi/viewcontent.cgi? article $=2422 \&$ context $=$ tqr . Accessed September 25, 2020.

22. Moher D, Liberati A, Tetzlaff J, Altman DG. Preferred reporting items for systematic reviews and meta-analyses: the PRISMA statement. BMJ. 2009;339(1):b2535. doi:10.1136/bmj.b2535

23. Bowling A. Research Methods in Health - Investigating Health and Health Services. Public Health. 2009;124(2):122.

24. CASP Checklist: 10 questions to help you make sense of a Qualitative research. Critical Appraisal Skills Programme. https://casp-uk.net/wp-content/uploads/2018/01/CASPQualitative-Checklist-2018.pdf. Accessed September 20, 2020.

25. Yu ESH, Chen EH, Kim KK, Abdulrahim S. Smoking Among Chinese Americans: Behavior, Knowledge, and Beliefs. Am J Public Health. 2002;92(6):1007-1013. doi:10.2105/AJPH.92.6.1007

26. Fu S, Ma G, Tu X, Siu P, Metlay J. Cigarette Smoking 
Among Chinese Americans and the Influence of Linguistic Acculturation. Nicotine Tob Res. 2003;5(6):803-811. doi:10.1080/14622200310001614566

27. Ma GX, Tan Y, Toubbeh JI, Su X, Shive SE, Lan Y. Acculturation and smoking behavior in Asian-American populations. Health Educ Res. 2004;19(6):615-625. doi:10.1093/her/cyg070

28. Shelley D, Fahs M, Scheinmann R, Swain S, Qu J, Burton D. Acculturation and Tobacco Use Among Chinese Americans. Am J Public Health. 2004;94(2):300. doi:10.2105/AJPH.94.2.300

29. Sussman NM, Truong N. "Please extinguish all cigarettes": The effects of acculturation and gender on smoking attitudes and smoking prevalence of Chinese and Russian immigrants. Int J Intercult Relat. 2011;35(2):163-178. doi:10.1016/j.ijintrel.2010.11.009

30. Petersen A, Tsoh J, Nguyen T, McPhee S, Burke N. Suffering in Silence: Impact of Tobacco Use on Communication Dynamics Within Vietnamese and Chinese Immigrant Families. J Fam Nurs. 2016;22(1):108-132. doi:10.1177/1074840715618194

31. Saw A, Paterniti D, Fung L-C, Tsoh JY, Chen MS, Jr, et al. Social Environmental Influences on Smoking and Cessation: Qualitative Perspectives among ChineseSpeaking Smokers and Nonsmokers in California. J Immigr Minor Health. 2017;19(6):1404-1411. doi:10.1007/s10903-016-0358-6

32. Gorman BK, Lariscy JT, Kaushik C. Gender, Acculturation, and Smoking Behavior among U.S. Asian and Latino Immigrants. Soc Sci Med. 2014;106:110-118. doi:10.1016/j.socscimed.2014.02.002

33. FitzGerald JM, Poureslami I, Shum J. Assessing beliefs and risk perceptions on smoking and smoking cessation in immigrant Chinese adult smokers residing in Vancouver, Canada: a crosssectional study. BMJ Open. 2015;5(2):e006435-e006435. doi:10.1136/bmjopen-2014-006435

34. Tsoh J, Lam J, Delucchi K, Hall S. Smoking and Depression in Chinese Americans. Am J Med Sci. 2003;326(4):187191. doi:10.1097/00000441-200310000-00007

35. Wu D, Ma GX, Zhou K, Zhou D, Liu A, Poon AN. The effect of a culturally tailored smoking cessation for Chinese American smokers. Nicotine Tob Res. 2009;11(12):14481457. doi:10.1093/ntr/ntp159

36. Cataldo J. High-risk older smokers' perceptions, attitudes, and beliefs about lung cancer screening. Cancer Med. 2016;5(4):753-759. doi:10.1002/cam4.617

37. Carter-Harris L, Brandzel S, Wernli KJ, Roth JA, Buist DSM. A qualitative study exploring why individuals opt out of lung cancer screening. Fam Pract. 2017;34(2):239244. doi:10.1093/fampra/cmw146

38. Delmerico J, Hyland A, Celestino P, Reid M, Cummings $\mathrm{K}$. Patient willingness and barriers to receiving a CT scan for lung cancer screening. Lung Cancer. 2014;84(3):307309. doi:10.1016/j.lungcan.2014.03.003

39. Duong DK, Shariff-Marco S, Cheng I, Naemi H, Moy
LM, Haile R, et al. Patient and primary care provider attitudes and adherence towards lung cancer screening at an academic medical center. Prev Med Rep. 2017;6:1722. doi:10.1016/j.pmedr.2017.01.012

40. Eberth J, Qiu R, Adams S, Salloum R, Bell N, Arrington A, et al. Lung cancer screening using low-dose CT: the current national landscape. Lung Cancer. 2014;85(3):379-384. doi:10.1016/j.lungcan.2014.07.002

41. Gressard L, DeGroff AS, Richards TB, Melillo S, Kish-Doto J, Heminger CL, et al. A qualitative analysis of smokers' perceptions about lung cancer screening. BMC Public Health. 2017;17(1):589. doi:10.1186/s12889-017-4496-0

42. Iaccarino J, Clark J, Bolton R, Kinsinger L, Kelley M, Slatore C, et al. A National Survey of Pulmonologists' Views on Low-Dose Computed Tomography Screening for Lung Cancer. Annals ATS. 2015;12(11):1667-1675. doi:10.1513/AnnalsATS.201507-4670C

43. Simmons V, Gray J, Schabath M, Wilson L, Quinn G. Highrisk community and primary care providers knowledge about and barriers to low-dose computed topography lung cancer screening. Lung Cancer. 2017;106:42-49. doi:10.1016/j.lungcan.2017.01.012

44. Raz D, Wu G, Consunji M, Nelson R, Kim, Sun C, et al. The Effect of Primary Care Physician Knowledge of Lung Cancer Screening Guidelines on Perceptions and Utilization of Low-Dose Computed Tomography. Clin Lung Cancer. 2018;19(1):51-57. doi:10.1016/j.cllc.2017.05.013

45. Lin J, Finlay A, Tu A, Gany F. Understanding immigrant Chinese Americans' participation in cancer screening and clinical trials. J Community Health. 2005;30(6):451-466. doi:10.1007/s10900-005-7280-5

46. Xu Y, Ross M, Ryan R, Wang B. Cancer risk factors of Vietnamese Americans in rural south Alabama [Internet]. Vol. 37, Journal of nursing scholarship: an official publication of Sigma Theta Tau International Honor Society of Nursing. J Nurs Scholarsh. 2005;37(3):237244. doi:10.1111/j.1547-5069.2005.00041.x

47. World Health Organization. Tobacco control in China. https://www.who.int/tobacco/about/partners/ bloomberg/chn/en/. Published November 2015. Accessed September 25, 2020.

48. Li S, Kwon S, Weerasinghe I, Rey M, Trinh-Shevrin C. Smoking among Asian Americans: acculturation and gender in the context of tobacco control policies in New York City. Health Promot Pract. 2013;14(Suppl 5):18S-28S. doi:10.1177/1524839913485757

49. Hu K, Woodall E, Do H, Tu S, Thompson, Acorda E, et al. Tobacco Knowledge and Beliefs in Chinese American Men. Asian Pac J Cancer Prev. 2006;7(3):434-438. PMID:17059339.

50. Nakamura N, Ialomiteanu A, Rehm J, Fischer B. Prevalence and characteristics of substance use among Chinese and south Asians in Canada. J Ethn Subst Abuse. 2011;10(1):39-47. doi:10.1080/15332640.2011.547794 51. Zhu SH, Wong S, Tang H, Shi CW, Chen M. High 
quit ratio among Asian immigrants in California: Implications for population tobacco cessation. Nicotine Tob Res. 2007;9(Suppl 3):S505-S514. doi:10.1080/14622200701587037

52. Wyatt L, Trinh-Shevrin C, Islam N, Kwon S. Healthrelated quality of life and health behaviors in a population-based sample of older, foreign-born, Chinese American adults living in New York City. Health Educ Behav. 2014;41(Suppl 1):98S-107S. doi:10.1177/1090198114540462

53. Lara M, Gamboa C, Kahramanian M, Morales L, Bautista D. Acculturation and Latino Health in the United States: A Review of the Literature and its Sociopolitical Context. Annu Rev Public Health. 2005;26:367-397. doi:10.1146/annurev.publhealth.26.021304.144615

54. Hunt L, Schneider S, Comer B. Should “acculturation" be a variable in health research? A critical review of research on US Hispanics. Soc Sci Med. 2004;59(5):973-986. doi:10.1016/j.socscimed.2003.12.009

55. Jenkins C, McPhee S, Le A, Pham G, Ha N, Stewart S. The effectiveness of a media-led intervention to reduce smoking among Vietnamese-American men. Am J Public Health. 1997;87(6):1031-1034. doi:10.2105/ajph.87.6.1031

56. Kuerban A. Healthy Migrant Effect on Smoking Behavior Among Asian Immigrants in the United States. J Immigrant Minority Health. 2016;18:94-101. doi:10.1007/s10903-014-0155-z

57. Corlin L, Woodin M, Thanikachalam M, Lowe L, Brugge D. Evidence for the healthy immigrant effect in older Chinese immigrants: a cross-sectional study. BMC Public Health. 2014;14:603. doi:10.1186/1471-2458-14-603

58. Li C, Matthews A, Dong X. The Influence of Health Literacy and Acculturation on Cancer Screening Behaviors Among Older Chinese Americans. Gerontol Geriatr Med. 2018;4:233372141877819. doi:10.1177/2333721418778193

59. Sentell T, Tsoh J, Davis T, Davis J, Braun K. Low health literacy and cancer screening among Chinese Americans in California: a cross-sectional analysis. BMJ Open. 2015;5(1):e006104. doi:10.1136/bmjopen-2014-006104
CONFLICTS OF INTEREST

The authors have completed and submitted the ICMJE Form for Disclosure of Potential Conflicts of Interest and none was reported.

FUNDING

There was no source of funding for this research.

AUTHORS' CONTRIBUTIONS

$\mathrm{FL}$ conceived and designed the study. $\mathrm{FL}$ and $\mathrm{YZ}$ collected the data. $\mathrm{FL}$ and $Y Z$ analyzed the data. FL initiated the manuscript drafting and $Y Z$ involved in revising the manuscript. All authors read and approved the final manuscript.

PROVENANCE AND PEER REVIEW

Not commissioned; externally peer reviewed. 